\title{
Erratum to: Extracellular monoenzyme deglycosylation system of 7-O-linked flavonoid $\beta$-rutinosides and its disaccharide transglycosylation activity from Stilbella fimetaria
}

\author{
Laura Mazzaferro $\cdot$ Lucrecia Piñuel •
}

Marisol Minig $\cdot$ Javier D. Breccia

Published online: 6 May 2011

(C) Springer-Verlag 2011

Erratum to: Arch Microbiol (2010) 192:383-393

DOI 10.1007/s00203-010-0567-7

Throughout the article, the fungus which was mentioned Stilbella fimetaria SES201 was re-identified as Acremonium sp. SES201.

Although the molecular analysis based on BLAST of the internal transcript spacer region (ITS) and of 5.8, 18 and
28S rDNA gave 99\% match with Stilbella fimetaria, the morphological analysis showed conidiophores that belong to Acremonium genus but not synnematous structures typical of Stilbella. The genera Acremonium and morphologically similar Stilbella have not yet been fully studied on a molecular basis. Under the morphological basis, the fungus was reidentified as Acremonium sp. SES201 = DSM 24697.

The online version of the original article can be found under doi:10.1007/s00203-010-0567-7.

L. Mazzaferro · L. Piñuel · M. Minig · J. D. Breccia $(\bowtie)$

CONICET (Consejo Nacional de Investigaciones Científicas y

Técnicas), Departamento de Química,

Facultad de Ciencias Exactas y Naturales,

Universidad Nacional de La Pampa (UNLPam),

Av. Uruguay 151, 6300 Santa Rosa, La Pampa, Argentina

e-mail: javierbreccia@exactas.unlpam.edu.ar 